\title{
Biodiesel Synthesis with Iron Oxide Nano-Catalyst Catalyzed Pongamia Pinnata Seed Oil and Dimethyl Carbonate
}

\author{
Balaji Panchal, Qin Shenjun*, Wang Jinxi, Bian Kai, Tao Chang* \\ Key Laboratory for Resource Exploration Research, Hebei University of Engineering, Handan, China \\ Email address: \\ qinsj528@hebeu.edu.cn (Qin Shenjun), changtao@hebeu.edu.cn (Tao Chang) \\ ${ }^{*}$ Corresponding author
}

To cite this article:

Balaji Panchal, Qin Shenjun, Wang Jinxi, Bian Kai, Tao Chang. Biodiesel Synthesis with Iron Oxide Nano-Catalyst Catalyzed Pongamia Pinnata Seed Oil and Dimethyl Carbonate. American Journal of Energy Engineering. Vol. 6, No. 3, 2018, pp. 21-28.

doi: 10.11648/j.ajee.20180603.11

Received: October 20, 2018; Accepted: November 2, 2018; Published: November 28, 2018

\begin{abstract}
The aim of this research was to investigate the biodiesel production from Pongamia pinnata seed oil and dimethyl carbonate with an iron oxide nano-catalyzed transesterification reaction. A significant biodiesel yield (96\%) was obtained with optimal operating conditions as the dimethyl carbonate to oil molar ratio (5:1), iron oxide nano-catalyst (50 $\mathrm{mg} \%$ based on oil weight), agitation speed of $150 \mathrm{rpm}$ and $60^{\circ} \mathrm{C}$ temperature for $5 \mathrm{~h}$ reaction time. The produced methyl esters from the transesterification process were confirmed to be almost identical to commercial standard biodiesel by thin layer chromatography. The produced methyl esters were analyzed by gas chromatography-mass spectrometry using an internal standard. Properties of methyl esters were characterized such as kinematic viscosity at $40^{\circ} \mathrm{C}$, specific gravity at $25^{\circ} \mathrm{C}$, flash point, cloud point, pour point, copper strip corrosion and acid value. The properties of the produced biodiesel were within the specifications of the American biodiesel standard, ASTM D6751-02. The results showed that all of tested reaction variables in this study had positive effects. In this research studied, a novel method has developed for production of biodiesel under mild conditions using DMC and iron oxide nano-catalyst. Iron oxide nano-catalyst could be potential candidate for use in the largescale biodiesel production.
\end{abstract}

Keywords: Pongamia Pinnata Oil, Iron Oxide Nano-catalyst, Dimethyl Carbonate, TLC, GC-MS

\section{Introduction}

Biodiesel, as a renewable source of bioenergy, has been produced from animal fats, vegetable oil, used cooking oils and algal lipids [1]. Biodiesel is a potential fuel because of its less polluting nature and lower amounts of carbon smoke [2]. Biodiesel is receiving increased acceptance in the market as an eco-environmentally friendly fuel [3]. Its physical properties are similar to those of petroleum diesel, which makes biodiesel a good alternative fuel [4].

Biodiesel seem to be useful, but its significant disadvantages include the cost of the oil sources and the limited availability of the oil crop for biodiesel production [5, 6]. Therefore, new feedstock suitable for biodiesel production must be found. One alternative to oil crops is the seed oil of $P$. pinnata because this plant contains high amounts of lipids, which make it suitable for biodiesel production [7]. In India, animal fats, edible and non-edible oil can be used for biodiesel production. $P$. pinnata plants can be grown in wastelands. The use of $P$. pinnata oil can thus likely provide an eco-environmentally acceptable fuel that will lead to reductions in the current diesel engine emissions [8].

Prior research has shown that a highly specific surface, catalysis activity and large porosity are beneficial for nanocatalysts to bind with the sub-layer, which enhances the efficacy of biodiesel production [9-11]. Catalytic technologies are critical to this chemical process [12].

The use of dimethyl carbonate (DMC) instead of methanol as an acyl acceptor in the biodiesel production process can solve the problem of the glycerol surplus, and using DMC produces glycerol-free biodiesel and glycerol carbonate (GC) 
as a valuable secondary product [13]. The generation of glycerol is avoided through the reaction of the oil feedstock and $\mathrm{DMC}$ to produce $\mathrm{GC}$, which does not require separation from the methyl ester [4, 14]. DMC is a neutral, non-toxic, and non-corrosive compound that exhibits good solvent properties $[15,16]$.

In this research, an iron oxide nano-catalyst is used in the transesterification reaction using $P$. pinnata seed oil as the feedstock. The effects of the nano-catalyst, reaction temperature, reaction time and DMC-to-oil molar ratio on the yield of biodiesel are examined. The stability of the nanocatalyst and its effects on yield levels are measured and discussed.

\section{Materials and Methods}

\subsection{Materials}

Iron oxide, with a $50 \mathrm{~nm}$ particle size (BET), was purchased from Sigma-Aldrich Company. Solvents and other analytical reagents were purchased from Merck. The chromatographic standards for fatty acid methyl esters were purchased from Bellefonte, USA. The gases used in the chromatographic analyses were purchased from White Martins. TLC silica gel $60 \quad \mathrm{~F}_{254}$ aluminum sheets were purchased from Merck Company.

\subsection{Pongamia Pinnata Seed Oil Contents}

$P$. pinnata is a nitrogen-fixing plant with seeds containing $28-36 \%$ oil. The molecular composition of $P$. pinnata oil is oleic acid (51.59\%), palmitic acid $(21.65 \%)$, stearic acid (7.5\%), linoleic acid (6.64\%), eicosanoic acid (1.35\%), dosocasnoic acid $(4.45 \%)$ and tetracosanoic acid (1.09\%) [17].

\subsection{Transesterification Process of P. Pinnata Oil Using Nano-catalysts}

$P$. pinnata oil was used as a reactant in the biodiesel transesterification process. First the $P$. pinnata oil was boiled at $50^{\circ} \mathrm{C}$ until a uniform liquid was produced. The reaction was performed in a $1000 \mathrm{~mL}$ glass batch reactor equipped with a heat exchanger to condense and return the DMC vapor to the reactor using a constant temperature bath. The molar ratio of $P$. pinnata oil to DMC varied from $1: 1$ to $6: 1$. The iron oxide nano-catalyst concentration was 10 to $60 \mathrm{mg} \%$ based on oil weight. The reaction temperature was varied from 15 to $75^{\circ} \mathrm{C}$ for the batch operation under standard conditions with a constant agitation speed of $150 \mathrm{rpm}$. The reaction was allowed to run for various reaction times, from 1 to $6 \mathrm{~h}$, to study the transesterification process. The sample was allowed to settle by gravity for $10 \mathrm{~h}$ after collection with a separation funnel, and it settled into a clear, golden liquid layer of biodiesel on top of a light brown glycerol carbonate layer. The glycerol carbonate was drained from the bottom of the separation funnel, and the remaining crude biodiesel was washed four times with Millipore water to remove the catalyst. To ensure the high purity of the biodiesel, a rotary evaporator was employed to remove excess DMC from the biodiesel. The high-purity biodiesel was dried with anhydrous sodium sulfate and then analyzed by TLC and gas chromatography-mass spectrometry (GC-MS), and the percentage of biodiesel yield was calculated. The biodiesel properties were determined by standard ASTM D6751-02 methods.

\subsection{Overall Reaction of Transesterification of P. Pinnata Oil with DMC}

"Figure 1", shows the biodiesel transesterification reaction of oil with DMC [18]. The products of the reaction are biodiesel and glycerol dicarbonate (GDC), which hydrolyzes to produce glycerol carbonate (GLC). The three reactions in the transesterification of triglyceride with $\mathrm{DMC}$ are as, the reaction of triglyceride (TG) with DMC to produce biodiesel and fatty acid glycerol carbonate (FAGLC); the further reaction of FAGLC with DMC to produce GDC and biodiesel; and the hydrolysis of GDC in an aqueous environment to produce GLC. GLC and GDC may be useful secondary products.

\subsection{Analysis of Biodiesel Used Nano-catalyst by GC-MS}

GC-MS has a combination of two different analytical techniques. Gas chromatography (GC) and mass spectrometry (MS) is used to analysis complex organic and biochemical mixture. $P$. pinnata seed oil biodiesel components were analyzed by GC-MS (model GC6890 N gas chromatograph, model MS5973 MSD mass selective detector). Separation was performed in a capillary column (DB-5MS, $30 \mathrm{~m} \times 0.32 \mathrm{~mm}, 0.25 \mu \mathrm{m}$ film thickness). The carrier gas was helium with a flow rate of $1.5 \mathrm{~mL} / \mathrm{min}$. The column temperature was programmed to increase from 120 to $280^{\circ} \mathrm{C}$ at a rate of $10^{\circ} \mathrm{C}$ per min. A sample volume of $0.1 \mu \mathrm{L}$ in chloroform was injected using split mode with a split ratio of $1: 10$. The mass spectrometer was set to scan the $\mathrm{m} / \mathrm{z}$ range from 50 to 550 using the electron impact (EI) ionization mode.

\subsection{Properties of Biodiesel Produced from P. Pinnata Oil Using Iron Oxide Nano-catalyst}

The biodiesel properties of the produced from $P$. pinnata oil using the iron oxide nano- catalyst were determined according to the ASTM D6751-02 specification. The specific gravity, kinematic viscosity, flash point, cloud point, pour point, copper strip corrosion and acid value were measured following ASTM D5002, ASTM D445, ASTM D93, ASTM D2500, ASTM D97, ASTM D130 and ASTM D664 [19].

\section{Result and Discussion}

\subsection{Iron Oxide Powder and Nano Particles}

Iron oxide nanoparticles are metal particles and comes in the size range of $10-100 \mathrm{~nm}$ (approx.). They are non-toxic in nature. Iron oxide nanoparticles readily form oxides. Iron 
nanoparticles possess high magnetic nature, high surface area, electrical and thermal conductivity. They also have excellent dimensional stability. Iron oxide nanoparticles it is even more rapid than the bulk material. This characteristic limits its use to inert environments. "Figure 2", shows the Iron oxide powder (A) and Iron oxide 10- 100nm nanoparticles (B).

\subsection{Biodiesel Determination by Thin Layer Chromatography}

Thin layer chromatography (TLC) is a rapid analytical technique that allows a qualitative indication of oil and biodiesel content in the mixture. "Figure 3", shows the TLC image for a biodiesel from transesterification reactions with the $50 \mathrm{mg} \%$ iron oxide nano-catalyst based on oil weight with optimum reaction conditions. The TLC procedure used a solvent containing hexane, ethyl acetate and glacial acetic acid at a ratio of 90:10:1 (v/v/v), respectively. Biodiesel produced from the $P$. pinnata seed oil using the iron oxide nano-catalyst showed higher vigor than did the oil, as indicated on the TLC plate with a clear phase separating the biodiesel from the feedstock. From the TLC analysis, it was confirmed that $50 \mathrm{mg} \%$ based on oil weight was the most suitable iron oxide nano-catalyst concentration for biodiesel production from $P$. pinnata oil. TLC was used to assess the conversion of oil to biodiesel [20] and to explore the use of the dominant fatty acids in safflower, soybean, sunflower, canola, corn and waste sunflower oil as biodiesel feedstock [21].

\subsection{Optimization of the Transesterification Reaction}

\subsubsection{Effect of Iron Oxide Nano-catalyst on Biodiesel Yield}

The effect of nano-catalyst loading on the transesterification of biodiesel was investigated with iron oxide nano-catalyst by varying the catalyst concentration from 10 to $60 \mathrm{mg} \%$ based on oil weight. The reaction was carried out at $60^{\circ} \mathrm{C}$ for $5 \mathrm{~h}$ with a 5:1 DMC to oil molar ratio. As shown in "Figure 4", when the nano-catalyst amount was increased from 10 to $50 \mathrm{mg} \%$ based on oil weight, the corresponding conversion to biodiesel gradually increased and obtained a maximum yield of $96 \%$. Varying the concentration of the nano-catalyst from 10 to $40 \mathrm{mg} \%$ based on oil weight did not result in a notable difference in the biodiesel percent yield. The biodiesel yield was found to decrease when the iron oxide nano-catalyst concentration was in excess of $60 \mathrm{mg} \%$ based on oil weight. Based on these results, $50 \mathrm{mg} \%$ of iron oxide nano-catalyst was optimal for these reaction parameters. Wang et al. [22] synthesized acidfunctionalized magnetic nano-particles and demonstrated their use as heterogeneous nano-catalysts for production of biodiesel. The biodiesel production of blend refined oil over novel promoted $\mathrm{Cs}-\mathrm{Ca} / \mathrm{TiO}_{2}-\mathrm{SiO}_{2}$ nano-catalysts was also investigated [23].

\subsubsection{Effect of Reaction Temperature on Biodiesel Yield}

Increases in temperature increase the kinetic energy of reactant particles, thus increasing the frequency of collision between reactants, which affects the rate of mass transfer between phases [24]. The reaction temperature was varied from 30 to $75^{\circ} \mathrm{C}$, with a constant iron oxide nano-catalyst concentration, a DMC to oil molar ratio of $5: 1$ and an agitation speed of $150 \mathrm{rpm}$. For the iron oxide nano-catalyst, the biodiesel yield gradually increased as the temperature increased at $60^{\circ} \mathrm{C}$, after which it tended to decrease slightly, as shown in "Figure 5 ". At $60^{\circ} \mathrm{C}$, the highest biodiesel yield of $96 \%$ was obtained, and the same yield was obtained at $75^{\circ} \mathrm{C}$; however, the iron oxide nano-catalyst gave only a $90 \%$ yield at $90^{\circ} \mathrm{C}$. Thereafter, the yield decrease with temperature was greater. At low temperatures $\left(30\right.$ to $\left.45^{\circ} \mathrm{C}\right)$, the reaction was not completed, so the yield was small. An increase in reaction temperature distributes energy to overcome the energy barrier for a reaction to proceed $[18,25]$. However, at higher reaction temperatures $\left(75\right.$ and $\left.90^{\circ} \mathrm{C}\right)$, a low biodiesel yield was obtained because the boiling point of DMC has at nearly the same temperature, and DMC may be lost as vapor [26]. Hence, $60^{\circ} \mathrm{C}$ was the optimum temperature for producing biodiesel from $P$. pinnata oil when using the iron oxide nano-catalyst.

\subsubsection{Effect of DMC-to-Oil Molar Ratio on Biodiesel Yield}

The reactant molar ratio is an important variable that affects the yield (\%) of biodiesel produced by transesterification [27]. The effect of the DMC to oil molar ratio on the biodiesel production is shown in "Figure 6". A biodiesel yield of $96 \%$ was obtained by increasing the molar ratio to 5:1. Generally, increasing the amount of alcohol increases the rate of reaction, resulting in a good yield of biodiesel in a short reaction time [28]. A decrease in the yield was observed when the molar ratio was increased beyond 5:1. Since excess DMC causes difficulties in heating, the DMC-to-oil molar ratio was maintained for a better transesterification process. Therefore, a DMC-to-oil molar ratio of 5:1 is suggested to be suitable for biodiesel production from $P$. pinnata oil. An excess of DMC possibly increased the polarity of the reaction suspension, thus developing a reverse reaction and decreasing the percentage of biodiesel yield [29]. Alia and Aziz [30] investigated the optimization of the transesterification reaction between palm oil and DMC with the aim of achieving a higher biodiesel yield.

\subsubsection{Effect of Reaction Time on Biodiesel Yield}

Balaji Panchal et al. [31] investigated the increases in the transesterification of fatty acid esters with increasing reaction times. The reaction time has an important effect on the biodiesel yield (\%) from $P$. pinnata oil. In this experiment, reaction times of $1,2,3,4,5$ and $6 \mathrm{~h}$ were used; all other conditions were kept constant. As shown in "Figure 7", the conversion increased with reaction time from 1 to $5 \mathrm{~h}$. The highest biodiesel yield, 96\%, was obtained within $5 \mathrm{~h}$, thereafter, biodiesel production slightly decreased. As reported by Patil et al. [32], an extended reaction time may result in the over-heating of the reaction suspension and 
solvent losses. Further, a longer reaction time decreases the biodiesel product due to the reversible reaction of transesterification, which causes a loss of methyl esters [33]. On the basis of the above results, the $5 \mathrm{~h}$ reaction time was considered as optimum for biodiesel production from $P$. pinnata oil using an iron oxide nano-catalyst, although shortening the reaction time may be more favorable for industrial applications.

\subsubsection{GC-MS Analysis of the Biodiesel Produced from P. Pinnata Oil}

GC-MS was used to identify the methyl esters in the biodiesel produced from $P$. pinnata seed oil, DMC and an iron oxide nano-catalyst. "Figure 8", shows the GC-MS results for biodiesel produced under optimal conditions. Ten characteristic peaks of methyl esters appeared in the GC-MS fragmentation pattern. The most abundant methyl ester components were $40.13 \%$ oleic acid methyl esters; $23.50 \%$ eicosenoic acid; $8.80 \%$ arachidic acid; $5.48 \%$ linoleic acid; $4.98 \%$ palmitic acid; $4.32 \%$ steric acid; $2.78 \%$ palmitoleic acid; $1.98 \%$ behenic acid; $0.96 \%$ alpha and gamma linoleic acid; and $0.87 \%$ docosanoic acid. The total yield of methyl esters was $96 \%$, suggesting high-quality biodiesel production from $P$. pinnata seed oil when using an iron oxide nanocatalyst. Hence, the iron oxide nano-catalyst has suitable for biodiesel production from $P$. pinnata oil and has recommended for industrial production of biodiesel.

\subsubsection{Properties of Biodiesel Produced from P. Pinnata Oil Using the Nano-catalyst}

Fabbri et al. [34] examined the chemical and physical properties of biodiesel. In the present research, the kinematic viscosity of the produced biodiesel has $4.9 \mathrm{~mm}^{2} / \mathrm{s}$ at $40^{\circ} \mathrm{C}$, and the specific gravity has $0.82 \mathrm{gm} / \mathrm{cm}^{3}$ at $25^{\circ} \mathrm{C}$. The fuel properties of the biodiesel from $P$. pinnata oil are shown in Table. $P$. pinnata oil biodiesel has a higher pour point and kinematic viscosity than doe's pure biodiesel $[35,36]$ and a higher cloud and pour point than doe's diesel fuel [37-39]. The pour and cloud points of the produced biodiesel using an iron oxide nano-catalyst ware 2 and 5, respectively. The acid value of the $P$. pinnata oil using iron oxide nano-catalyst biodiesel produced in the research has $0.30 \mathrm{mgKOH} / \mathrm{g}$. The flash point of the $P$. pinnata oil using iron oxide nanocatalyst was $119^{\circ} \mathrm{C}$. Biodiesel has a high flash point, which usually exceeds $150^{\circ} \mathrm{C}$, whereas conventional diesel fuel generally has a flash point in the range of 55 to $66^{\circ} \mathrm{C}$ [40]. The flash point is a measure of the flammability of fuels and an important parameter for assessing hazards during fuel transport and storage [41, 42].

\section{Conclusions}

We found that this new approach could decrease both the production reaction time and temperature and that using a low iron oxide nano-catalyst concentration provides higher biodiesel yields that can even reach $96 \%$. The production of biodiesel from $P$. pinnata oil with DMC was successfully conducted using an iron oxide nano-catalyst. A DMC to $P$. pinnata oil molar ratio of $5: 1$ is very effective and economically viable. Based on the experimental results, it is possible to conclude that a $5 \mathrm{~h}$ reaction time, $50 \mathrm{mg} \%$ iron oxide nano-catalyst based on oil weight, $60^{\circ} \mathrm{C}$ reaction temperature and $150 \mathrm{rpm}$ agitation speed were the best experimental conditions for achieving the maximum biodiesel yield of $96 \%$. The properties of the resulting biodiesel met the specifications of the biodiesel standard ASTM D6751-02. This biodiesel production process has a relatively low cost because of the $P$. pinnata oil starting material, a low iron oxide nano-catalyst concentration and a short reaction time, so we consider it to be an economical fuel solution.

\section{Appendix}

Table 1. Properties of biodiesel using iron oxide nano-catalyst with P.pinnata oil compared with ASTM D6751-02 specification.

\begin{tabular}{|c|c|c|c|c|}
\hline Biodiesel properties & Units & Methods & ASTM Limits & Obtained result \\
\hline Kinematic viscosity at $40^{\circ} \mathrm{C}$ & $\mathrm{mm}^{2} / \mathrm{sec}$ & D445 & $1.9-6.0$ & 4.9 \\
\hline Specific gravity at $25^{\circ} \mathrm{C}$ & $\mathrm{gm} / \mathrm{cm}^{3}$ & D4052 & Reports & 0.82 \\
\hline Pour point & ${ }^{\circ} \mathrm{C}$ & D93 & Reports & 2 \\
\hline Cloud point & ${ }^{\circ} \mathrm{C}$ & D2500 & Reports & 5 \\
\hline Flash point & ${ }^{\circ} \mathrm{C}$ & D5950 & Reports & 119 \\
\hline Copper strip corrison $\left(3 \mathrm{hrs}\right.$ at $\left.50^{\circ} \mathrm{C}\right)$ & 1 & D130 & Max no.3 & $1 \mathrm{a}$ \\
\hline Acid values & $\mathrm{mg} \mathrm{KOH} / \mathrm{g}$ & D664 & Max 0.50 & 0.3 \\
\hline Water and sediment $\%$ vol. max & $\%$ vol. & D2709 & 0.05 & 0.009 \\
\hline Carbon residue & $\mathrm{wt} \%$ & D45309 & 0 & 0 \\
\hline Ash content & $\mathrm{wt} \%$ & D874 & Max 0.02 & 0.007 \\
\hline
\end{tabular}




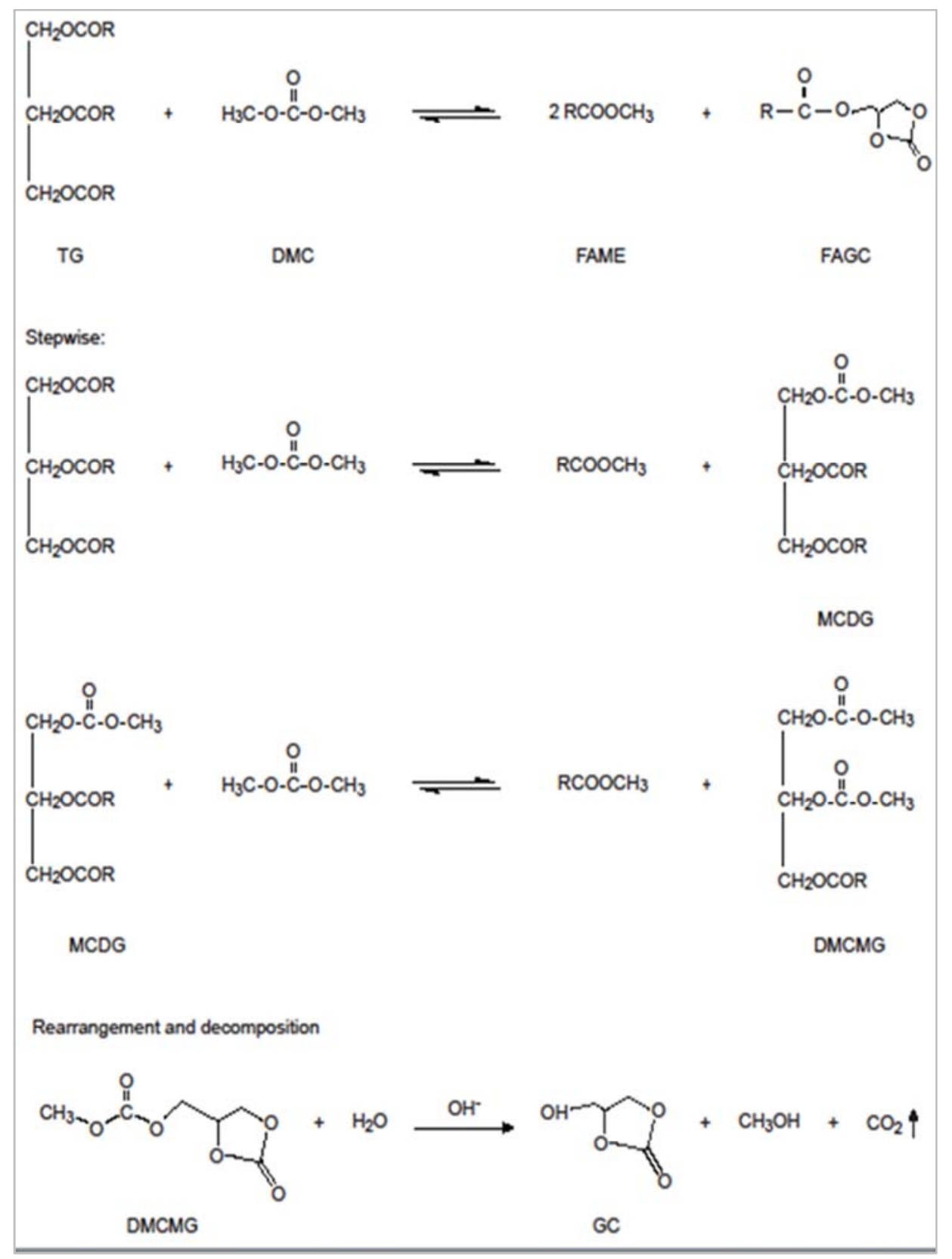

Figure 1. Transesterification reaction of triglyceride with DMC.

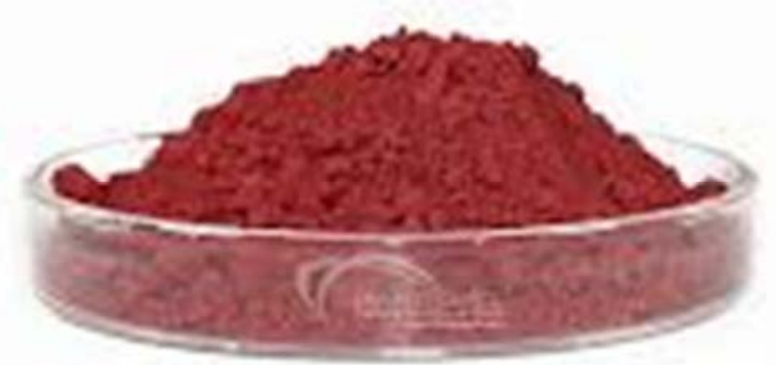

(A)

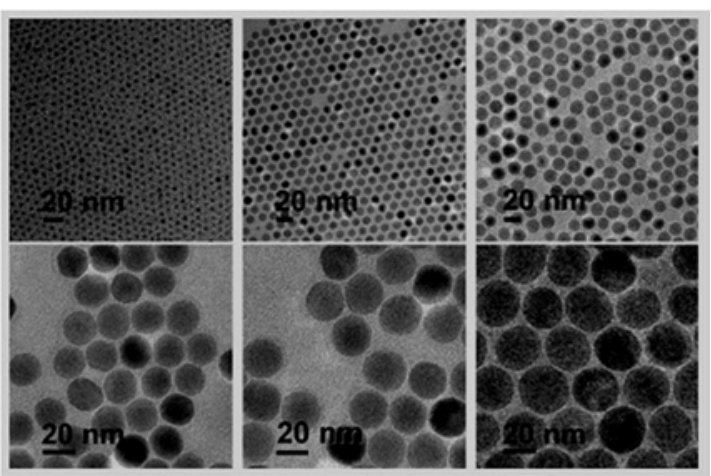

(B)

Figure 2. Images of Iron oxide powder (A) and Iron oxide 10- 100nm nano particles (B). 


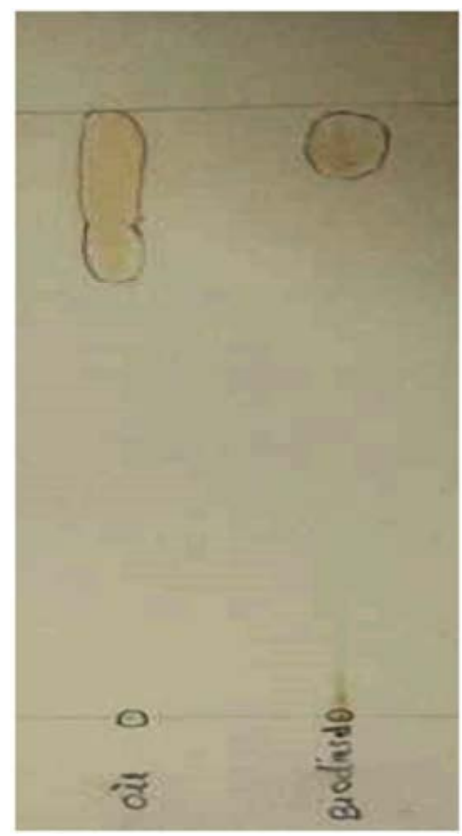

Figure 3. Biodiesel analysis by thin layer chromatography. Reaction conditions: 5:1 molar ratio of DMC to P. pinnata oil, 150 rpm agitation speed for 5 h, $50 \mathrm{mg} \%$ iron oxide nano-catalyst in P. pinnata oil and reaction temperature of $60^{\circ} \mathrm{C}$.

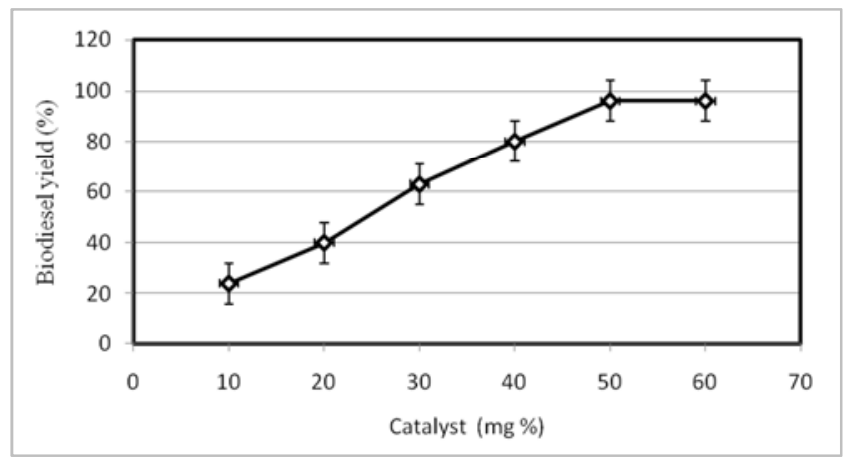

Figure 4. Effect of iron oxide nano-catalyst concentration on biodiesel yield. Reaction conditions: 5:1 molar ratio of DMC to P.pinnata oil, $150 \mathrm{rpm}$ agitation speed at $60^{\circ} \mathrm{C}$ for $5 \mathrm{~h}$ and various iron oxide nano-catalyst concentrations. Data represent the mean \pm standard deviation of triplicate observations.

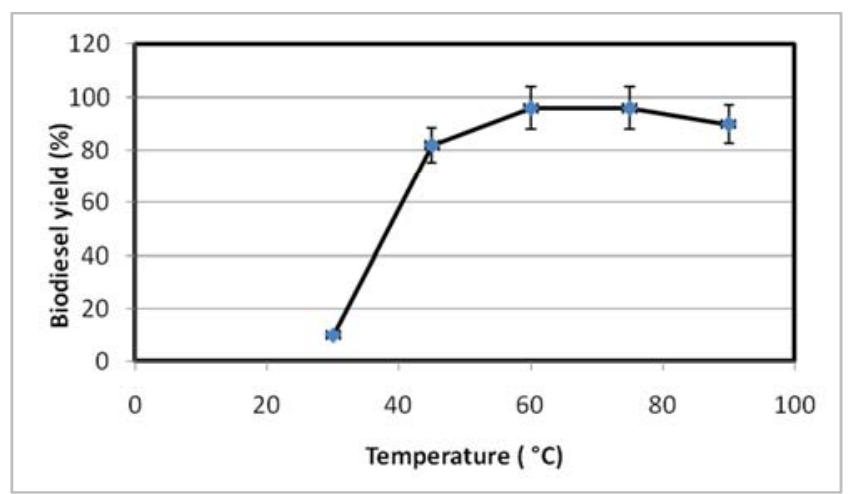

Figure 5. Effect of reaction temperature on biodiesel yield. Reaction conditions: 5:1 molar ratio of DMC to P. pinnata oil, $150 \mathrm{rpm}$ agitation speed for 5 h, $50 \mathrm{mg} \%$ iron oxide nano-catalyst in P. pinnata oil and various reaction temperatures $i^{\circ} \mathrm{C}$. Data represent the mean \pm standard deviation of triplicate observations.

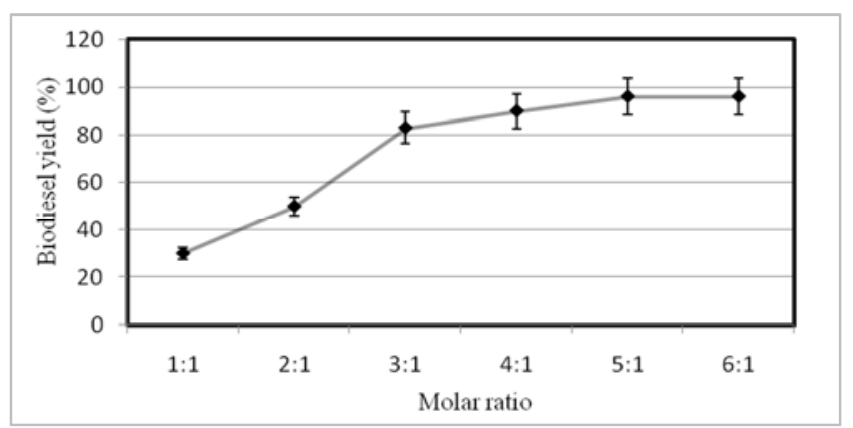

Figure 6. Effect of the DMC to P. pinnata oil molar ratio on biodiesel yield. Reaction conditions: $50 \mathrm{mg} \%$ iron oxide nano-catalyst in P. pinnata oil, 150 rpm agitation speed at $60^{\circ} \mathrm{C}$ for $5 \mathrm{~h}$ and various DMC to P. pinnata oil molar ratios. Data represent the mean \pm standard deviation of triplicate observations.

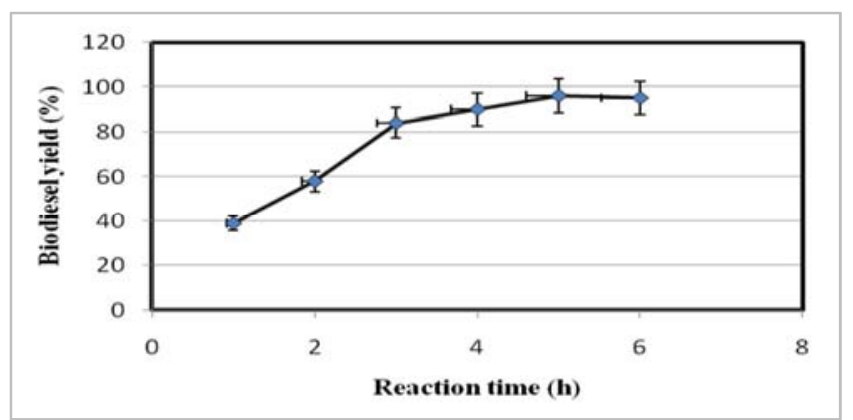

Figure 7. Effect of reaction time on biodiesel yield. Reaction conditions: 50 $m g \%$ iron oxide nano-catalyst in P. pinnata oil, DMC to P. pinnata oil molar ratio, $150 \mathrm{rpm}$ agitation speed at $60^{\circ} \mathrm{C}$ and various reaction times in hours. Data represent the mean \pm standard deviation of triplicate observations.

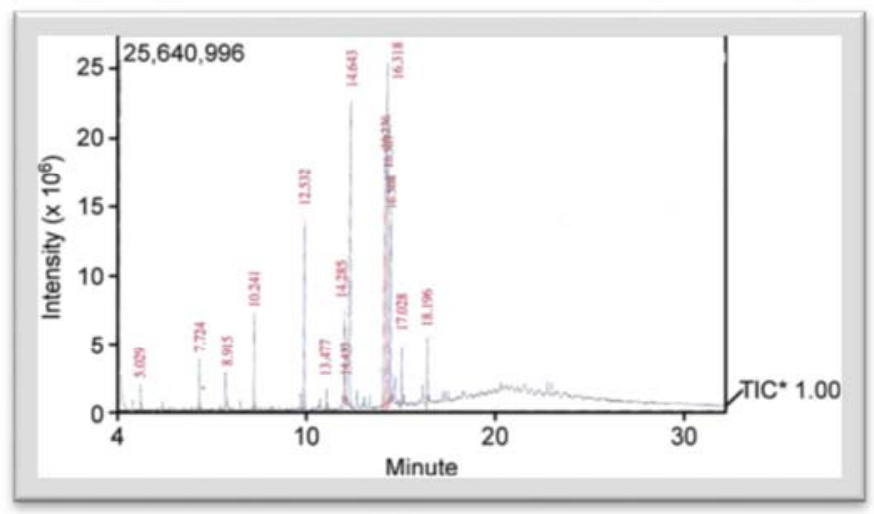

Figure 8. Chromatogram of biodiesel from P. pinnata oil and DMC using an iron oxide nano-catalyst.

\section{References}

[1] W-Y. Choi, G-V. Kim, S-Y. Lee, H-Y. Lee, Biodiesel production from Scenedesmus sp. through optimized in situ acidic transesterification process. Chem. Biochem. Eng Q 2014, 28 (3): 367-74.

[2] R. Murmu, H. Sutar1, S. Patra, Experimental investigation and process optimization of biodiesel production from kusum oil using taguchi method. Adv. Chem. Engineer. Sci 2017, 7: 464-76. 
[3] H. C. Onga, T. M. I. Mahliaa, H. H. Masjuki, R. S. Norhasyima, Comparison of palm oil, Jatropha curcas and Calophyllum inophyllum for biodiesel: A review. Renew. Sust Energ. Rev 2011, 15: 3501-15.

[4] Y. Tang, H. Ren, F. Chang, X. Gu, J. Zhang, Nano KF/Al2O3 particles as an efficient catalyst for no-glycerol biodiesel production by coupling transesterification. Roy. Soc. Chem 2017, 7: 5694-700.

[5] A. Demirbas, Importance of biodiesel as transportation fuel. Energ. Policy 2007, 35: 4661-70.

[6] Y. Chisti, Biodiesel from microalgae beats bioethanol. Cell. Press 2008, 26: 126-31.

[7] S. N. Bobade, V. B. Khyade, Preparation of methyl ester (Biodiesel) from Karanja (Pongamia oinnata) oil. Res. J. Chem. Sci 2012, 2(8): 43-50.

[8] J. Hill, E. Nelson, D. Tilman, D., 2006. Environmental, economical energetic costs and benefits of biodiesel and ethanol biofuels. Proc. Natl. Acad. Sci 2006, 103: 11206-210.

[9] L. Bournay, D. Casanave, B. Delfort, G. Hillion, J. A Chodorge, New heterogeneous process for biodiesel production: A way to improve the quality and the value of the crude glycerine produced by biodiesel plants. Catal. Today 2005, 106: 190-92.

[10] Q. Shu, B. Yang, H. Yuan, S. Qing, G. Zhu, Synthesis of biodiesel from soybean oil and methanol catalyzed by zeolite beta modified with $\mathrm{La}^{3+}$. Catal. Commun 2007, 8: 2159- 165.

[11] T. Kambiz, N. A. Yasaman, F. Reza, M. Sogol, D. Elham, D., 2015. The study of $\mathrm{CaO}$ and $\mathrm{MgO}$ heterogenic nano-catalyst coupling on transesterification reaction efficacy in the production of biodiesel from recycled cooking oil. J. Environ. Heal. Sci. Eng 2015, 13:73. DOI 10.1186/s40201-015-0226770 .

[12] S. Chaturvedi, N. Pragnesh, N. K. Dave, Shah, Applications of nano-catalyst in new era. J. Saudi. Chem. Soc 2012, 16: $307-$ 25 .

[13] Y. M. Kurle, M. R. Islam, T. J. Benson, Process development and simulation of glycerol-free biofuel from canola oil and dimethyl carbonate. Fuel. Process. Technol 2013, 114(0): 4957.

[14] D. Delledonne, F. Rivetti, U. Romano, Synthesis of dimethyl carbonate from oxidative carbonylation of methanol catalyzed by $\mathrm{Cu}$ (phen) Cl2. Appl. Catal. A 2001, 221: 241-51.

[15] Y. Syamsuddina, B. H. Hameeda, Synthesis of glycerol freefatty acid methyl esters from Jatropha oil over Ca-La mixedoxide catalyst. J. Taiwan. Inst. Chem. Eng 2015, 1-8.

[16] L. Zhang, B. Sheng, Z. Xin, Q. Liu, S. Sun, Kinetics of transesterification of palm oil and dimethyl carbonate for biodiesel production at the catalysis of heterogeneous base catalyst. Bioresour. Technol 2010, 101(21): 8144-50.

[17] S. V. A. R. Sastry, C. V. R. Murthy, Synthesis of biodiesel by In-situ transesterification of Karanja oil. Bangladesh. J. Sci. Ind. Res 2014, 49(4): 211-18.

[18] A. Folasegun, O. A. Olubunmi, X. Jiayu, Z. Suojiang, Dimethyl carbonate mediated production of biodiesel at different reaction temperatures. Rene. Energ 2014, 68: 581-87.
[19] M. Rengasamy, K. Anbalagan, S. Mohanraj, Biodiesel production from pongamia pinnata oil using synthesized iron nanocatalyst. Int. J. Chem. Tech. Res 2014, 6(10): 4511-516.

[20] O. Babajide, L. Petrik, N. Musjoka, B. Amigun, F. Ameer, Use of coal fly ash as catalyst in the production of biodiesel. Pet. Coal 2010, 2(4): 216-72.

[21] S. Ayten, M. O. Hakki, S. I. Sebnem, P. Hatice, M. Neslihan, Toprakkiran, Alkali catalysis of different vegetable oils for comparisons of their biodiesel productivity. J. Sust. Bioenerg. Syst 2013, 3 (1): 79-85.

[22] H. Wang, J. Covarrubias, H. Prock, X. Wu, D. Wang, S. H. Bossmann, Acid- functionalized agnetic nanoparticle as heterogeneous catalyst for biodiesel synthesis. J. Phys. Chem. C 2015, 119: 26020-28.

[23] M. Feyzi, E. Shahbazi, Catalytic performance and characterization of $\mathrm{Cs}-\mathrm{Ca} / \mathrm{SiO}_{2}-\mathrm{TiO}_{2}$ nanocatalysts for biodiesel production. J. Mole. Catal. A. Chem 2015, 404- 405: 131-38.

[24] A. Ramli, M. Farooq, Optimization of process parameters for the production of biodiesel from waste cooking oil in the presence of bifunctional c- $\mathrm{Al}_{2} \mathrm{O}_{3}-\mathrm{CeO}_{2}$ supported catalysts. Malays. J. Anal. Sci 2015, 19 (1): 8-19.

[25] A. Hayyan, M. Z, Alam, E. S. Mirghani, N. A. Kabbashi, N. Hakimi, Y. Siran, S. Tahiruddin, Sludge palm oil as a renewable raw material forbiodiesel production by two-step processes. Bioresour. Technol 2010, 101: 7804-811.

[26] B. D. Patil, V. G. Gude, S. Deng, Biodiesel production from Jatropha curcas, waste cooking, and Camelina sativa oils. Ind. Eng. Chem. Res 2009, 48: 10850-856.

[27] Y. Syamsuddin, Y. M. N. Murat, B. H. Hameed, Synthesis of fatty acid methyl ester from the transesterification of high- and low-acid-content crude palm oil (Elaeis guineensis) and karanj oil (Pongamia pinnata) over a calciumlanthanum-aluminum mixed-oxides catalyst. Bioresour. Technol 2016, 214: 248-52.

[28] P. Chattip, P. Prasert, T. Q. Armando, G. Motonobu, S. Artiwan, Microalgal lipid extraction and evaluation of singlestep biodiesel production. Eng. J 2012, (5): 16, http://dx.doi.org/10.4186/ej.2012.16.5

[29] G. K. Ayetor, A. Sunnu, J. Parbey, Effect of biodiesel production parameters on viscosity and yield of methyl esters: jatropha curcas, Elaeis guineensis and Cocos nucifera. Alex. Eng. J 2015, 54 (4): 1285-90.

[30] N. A. M. Alia, N. Aziz, Optimization of DMC transesterification based biodiesel production. Adv. Mate. Res 2015, 1113: 370-75.

[31] B. M. Panchal, S. A. Deshmukh, M. R. Sharma, Production and kinetic transesterification of biodiesel from yellow grease with dimethyl carbonate using methanesulfonic acid as a catalyst. Environ. Prog. Sust. Energ 2017 DOI: 10.1002/ep.12559.

[32] P. D. Patil, V. G. Gude, A. Mannarswamy, S. Deng, P. Cooke, S. Munson-McGee, I. Rhodes, P. Lammers, N. N. Khandan, Optimization of direct conversion of wet algae to biodiesel under supercritical methanol conditions. Bioresour. Technol 2011, 102(1): 118-22. 
[33] T. Eevera, K. Rajendran, S. Saradha, Biodiesel production process optimization and characterization to assess the suitability of the product for varied environmental conditions. Rene. Energ 2009, 34(3): 762-65. doi: 10.1016/j.renene.2008.04.006.

[34] D. Fabbri, V. Bevoni, M. Notari, F. Rivetti, Properties of a potential biofuel obtained from soybean oil by transmethylation with dimethyl carbonate. Fuel 2007, 86: 690-97.

[35] G. Knothe, K. R. Steidley, Kinematic viscosity of biodiesel fuel components and related compounds. Influence of compound structure and comparison to petro diesel fuel components. Fuel 2005, 84: 1059-65.

[36] M. Lapuerta, J. Rodríguez-Fernández, C. Estevez, N. Bayarri, Properties of fatty acid glycerol formal ester (FAGE) for use as a component in blends for diesel engines. Biomass. Bioenerg 2015, 76: 130-40.

[37] A. Demirbas, Progress and recent trends in biodiesel fuels. Energ. Conver. Manag 2009, 50(1): 14-34. doi: 10.1016/j. enconman.2008.09.001.
[38] P. Nakpong, S. Wootthikanokkhan, Optimization of biodiesel production from Jatropha curcas L. oil via alkali-catalyzed methanolysis. J. Sust. Energ. Environ 2010, 1: 105-09.

[39] M. P. Dorado, E. Ballesteros, F. J. Lopez, M. Mittelbach, Optimization of alkali- catalyzed transesterification of Brassica Carinata oil for biodiesel production. Energ. Fuel 2004, 18: 77-83.

[40] L. Meher, D. Vidyasagar, S. Naik, Technical aspects of biodiesel production by transesterification-a review. Rene. Sust. Energ. Rev 2006 10(3): 248-68. doi: 10.1016/j.rser. 2004.09.002.

[41] R. Rubi, L. M. Sandra, N. Reyna, Biodiesel production by using heterogeneous catalysts. Altern. Fuel 2011, 1-20.

[42] S. Fernando, P. Karra, R. Hernandez, Effect of incompletely converted soybean oil on biodiesel quality. Energ 2007, 32(5): 844-51. 